\title{
Entre brincadeiras e homenagens: a experiência social infantil em Isola Sacra (séculos I e II)
}

\author{
Amid play games and commemoration: infant social experience \\ in Isola Sacra ( $7^{\text {st }}$ and $2^{\text {nd }}$ centuries CE)
}

\section{Luciane Munhoz de Omena*}

\begin{abstract}
Resumo: $O$ artigo visa à reflexão sobre a socialização infantil no Mediterrâneo romano, especialmente na necrópole de Isola Sacra, que se localiza entre Óstia e Portus. Verifica-se a presença de crianças no espaço funério. Meninos e meninas aparecem homenageados em uma grande variedade de suportes como estelas, altares, retratos, sarcófagos, que registram o luto, o sentimento de perda, a individualidade e seus ambientes de entretenimento, nascimento, educação, entre outros mais. Partindo, então, dessas observações, propõe-se compreender a experiência social infantil em testemunhos escritos e materiais acerca do brincar e do educar. Em um segundo momento, o estudo se envereda rumo às comemorações mortuárias às crianças nos epitáfios presentes em Isola Sacra.
\end{abstract}

\begin{abstract}
The paper aims at reflecting on infant socialization in the Roman Mediterranean, especially in the necropolis of Isola Sacra, located between Ostia and Portus. The presence of children is verified in the funereal site. Boys and girls are seen as commemorated in a wide range of mediums such as steles, altars, portraits, sarcophagi, which portray the mourning, the feeling of loss, individuality and their entertainment, birth, education environments, among others. From these observations, therefore, it is proposed to understand infant social experience in written testimonies and material related to jesting and educating. In a second stage, the study engages towards funeral commemoration for the children in existing epitaphs in Isola Sacra.
\end{abstract}

Palavras-chave: Experiência Social. Brincadeiras.

Morte.

Infantil.

Epitáfios.

Keywords:

Social Experience.

Play Games.

Death.

Infant.

Epitaphs.

\footnotetext{
* Professora Associada III da Faculdade de História e do Programa de Pós-Graduação em História da Universidade Federal de Goiás (UFG).
} 


\section{Introdução}

o estudarmos os rituais mortuários vinculados à infância, deparamo-nos com
dinâmicas socioculturais. Sabemos que as experiências sociais produzem, atribuem e
expressam significados à sociedade (TUAN, 1983, p. 6-7). Logo, entender a morte e a infância na região mediterrânica de Isola Sacra, localizada entre Óstia e Portus, nas imediações do aeroporto Fiumicino, de Roma, exige-nos um mergulho em suas especificidades. Embora a morte a todos espreite, os rituais de descartes e seus símbolos não são universais. Os edifícios funerários de Isola Sacra datam da metade do século I ao IV, e não se registram grupos sociais afiliados às ordens senatorial e equestre. As evidências epigráficas e os relevos indicam a presença de mercadores, médicos, parteiras, comerciantes, sacerdotes, escravos, libertos, entre outros mais; portanto, os papéis atribuídos às crianças e seus enterramentos se associam ao ambiente portuário, ao status social e aos ofícios dos familiares.

Segundo se propõe, existem múltiplas vivências no espaço-tempo. Parece uma resultante evidente. No entanto, é necessário reforçarmos as perspectivas histórica e arqueológica, já que, como sustenta Eva Jane Baxter (2008, p. 160), as interpretações arqueológicas apresentaram, de forma sintomática, dois segmentos de análise: crianças e infância aparecem relacionadas ao conceito de maturidade. ${ }^{1}$ Nesta vertente, argumenta-se que a Arqueologia veiculava ideias de que crianças deveriam ser cuidadas, controladas e mantidas em segurança entre seu nascimento e a vida adulta. O segundo segmento de análise acentuava os aspectos biológicos e o desenvolvimento físico. Em suas pesquisas, teríamos a aplicação dos estágios identificáveis como bebês, crianças, adolescentes, adultos e idosos, produzindo, com isso, uma retórica que se fundamentava em certa naturalização da infância como expressão universal (BAXTER, 2008, p. 161). Todos os indivíduos vivenciariam o ciclo de vida, excluindo, dessa forma, as experiências sociais e suas atribuições e significados que, produzidos historicamente, alteram essas percepções cíclicas.

Partindo dessas perspectivas, o artigo propõe dois caminhos que se interconectam: a espacialização da criança e os usos simbólicos dos brinquedos, uma vez que, em se tratando de sepultamentos, com frequência, evidências materiais de brinquedos ou suas representações imagéticas compõem os bens móveis e imóveis das sepulturas. Em seguida, a proposta envereda pelas reflexões acerca de epitáfios do século II, os quais, localizados em Isola Sacra, homenageiam crianças falecidas. Passemos, então, à discussão.

\footnotetext{
${ }^{1}$ É ainda necessário enfatizar as diferenças conceituais entre criança e infância, pois, como indica Luana Neres Sousa (2019, p. 2), "criança está ligado ao biológico, à determinada fase de desenvolvimento em que o ser humano se encontra, enquanto infância é um conceito abstrato e diz respeito ao modo como as sociedades compreendem e se relacionam com as crianças". Consultar Grubbs e Parkin (2013, p. 1-16).
} 


\section{O brincar e o aprender nas narrativas itálicas à luz de evidências escritas e materiais}

As narrativas da infância na Antiguidade nos suscitam, no mínimo, curiosidade. Voltamos nossos pensamentos às brincadeiras como bolinhas de gude, queimada, travalíngua, amarelinha, bambolê, cavalo de pau, jogos de tabuleiro, e tantas outras que nortearam a nossa experiência social. O menino e a menina marcam os ambientes e os objetos da infância, se tornam agentes mnemônicos, pois nosso cotidiano entremeado de brincadeiras, rotina de estudos e obrigações domésticas compõe normalmente nossas reminiscências.

Evidências arqueológicas retratam a valorização das crianças e da infância nas sociedades grega e romana. ${ }^{2}$ Por exemplo, no sítio arqueológico de Conimbriga, província da Lusitânia, escavações descortinaram artefatos que se vinculavam às experiências educacionais e aos entretenimentos, como, por exemplo, casinhas (simulacra domuum), carrinhos (plostella), bonecas (pupae), soldados (ducatus aut imperia), entre outros mais (PESSOA et al., 2000). Tais artefatos conduzem a questões que, exploradas por Mary Harlow (2013, p. 324), em seu artigo Toys, dolls, and the material culture of childhood, conduziram-na a indagar se os bens deveriam comemorar e representar o ente querido, se serviam a um propósito específico da vida no post mortem, se atuariam na projeção familiar dentro da comunidade, se idealizariam a educação da criança falecida, se estavam associados ao culto aos mortos e, assim, consecutivamente.

À vista disso, cabe explicitarmos o quão complexo se representa o contexto em que os brinquedos são encontrados nos sítios arqueológicos, pois, como versa a discussão fundamentada em Mary Harlow (2013, p. 322) e Norberto Luiz Guarinello (2011, p. 162), o brinquedo como objeto poderia compor ou não o universo das crianças. Sabemos que as crianças não se restringiam apenas aos seus espaços e objetos; podiam - e ainda podem, em nosso período - transformar qualquer objeto em brinquedo. Vassouras se convertiam em cavalos. Caroços de frutas se tornavam bonecos. Nozes se transformavam em objetos de jogos, entre outras possibilidades. De todo modo, o brincar de casinha, especificamente, estimularia a criança a se preparar para a vida social, numa espécie de imitação.

Ao mencionar a relação entre a ama e a criança, Quintiliano (30 a 40-100) afirma:

O menino as ouvirá logo no início, tentará reproduzir as palavras delas por imitação e, por natureza, somos muito aferrados àquilo que percebemos com o espírito intocado: como o sabor, pelo qual incutas algo novo, permanece, também as cores das lãs, com que aquele branco simples foi mudado, podem ser desfeitas. E essas coisas se fixam mais tenazmente sendo as piores. Realmente, as coisas boas se alteram para o pior: quando convertes os vícios em algo bom? Portanto, não

2 Para maiores informações sobre as concepções acerca da criança e infância em sociedades gregas, consultar Sousa, 2019; Oakley, 2013; Golden, 2011; Macniven, 2007. 
o acostumes à linguagem, que não deve ser sabida, mesmo enquanto for criança (Quintiliano, Institutio Oratoria, I, 5). ${ }^{3}$

Nesta passagem, o orador enfatiza os processos de imitação e socialização das crianças no ambiente doméstico. As amas deveriam ter uma linguagem mais polida, já que as crianças, em fases iniciais, imitavam seus cuidadores. ${ }^{4}$

Como apontam Crawford, Hadley e Shepherd (2018, p. 18-20), compreender a espacialização da criança no ambiente doméstico converge em desafios para arqueólogos e, diria para os historiadores, reconhecerem que uma escavação evidencia estruturas em estado de mudança. Não representa uma estrutura estática. É importante a identificação dos espaços das crianças nos registros arqueológicos, bem como objetos que podem se tornar brinquedos; todavia, como supõem os pesquisadores, é imprescindível reconhecer que o uso e o acesso aos espaços podem sofrer variações nos diferentes momentos do dia. Por exemplo, crianças poderiam usar os átrios como ambiente de recreação, mas somente após o término dos negócios e das reuniões de adultos.

Nesse sentido, o diálogo entre os registros materiais e textuais ressaltam, segundo se propõe, sob as vias da educação e das brincadeiras, as projeções dos adultos para a infância. As pesquisas de Harlow (2013, p. 325-326) indicam a especificidade na produção de brinquedos, como, por exemplo, chocalhos, que possuíam formas e tamanhos variados, sendo produzidos com materiais de prata, bronze e terracota. Alguns deles eram moldados

\footnotetext{
${ }^{3}$ Has primum audiet puer, harum verba effingere imitando conabitur. Et natura tenacissimi sumus eorum, quae rudibus animis percepimus; ut sapor, quo nova imbuas, durat, nec lanarum colores, quibus simplex ille candor mutatus est, elui possunt. Et haec ipsa magis pertinaciter haerent, quo deteriora sunt. Nam bona facile mutantur in peius; num quando in bonum verteris vitia? Non assuescat ergo, ne dum infans quidem est, sermoni qui dediscendus sit.

${ }^{4}$ Segundo Quintiliano (Inst., I, 4), a nutrix (ama) cuidava da manutenção física e emocional da criança, alimentava-a, brincava e dormia com ela. Assim como as amas, os pais se preocupavam com a educação, a disciplina e o desenvolvimento social de crianças pequenas (ALLISON, 2018, p. 4). Logo, identificam-se, nos vestígios materiais e textuais (e.g. Plutarco, Moralia, 20, 03), a presença de chocalhos, piões, bolas, nozes, bonecas e carrinhos (RAWSON, 2003; HARLOW, 2013). É relevante frisarmos que a criança recebia os cuidados dos pais e do escravo que se denominava pedagogo. Este "geralmente grego, que acompanhava sempre uma criança, inclusive à escola. Em certos contextos, tem o sentido de "guia", "condutor", "mentor"" (BASSETTO, 2015, p. 215). Normalmente, aos sete anos, as crianças se dirigiam às escolas. Nesta etapa, teríamos o fim da primeira infância e a idade em que a nutrix seria substituída por um paedagogus, e as crianças, meninos e meninas, deixariam suas famílias para serem educadas na escola (ALLISON, 2018, p. 5). Dessa forma, a maioridade de uma menina chegava aos 12 anos, quando, neste período, deixava a infância. Passava a ser destinada ao matrimônio. A maioridade do menino vinha aos 14 anos, momento que vestia a toga uirilis, abandonando, portanto, a pueritia (infância, adolescência etc. (SARAIVA, 1993; HORNBLOWER et al., 2012). Passavam, com isso, aos estudos filosóficos e retóricos (RAWSON, 2003, p. 134-144), bem como se dedicavam aos exercícios físicos nas palaestrae e, em seguida, mergulhavam em uma piscina ao ar livre (FERREIRA, 2000, p. 44). Como indica Allison (2018, p. 5-6), o universo dessa educação se dirigia às crianças de famílias abastadas, mas e quanto às crianças pobres ou escravas? Estas dedicavam-se às tarefas domésticas, em especial ao manuseio de vasos, alimentos líquidos, e trabalhavam em cozinhas, com galinhas, colhiam madeiras, cuidavam e educavam crianças mais novas. Em Roma, no Palatino, temos a presença de uma escola (o paedagogium) para escravos e libertos imperiais (KEEGAN, 2013). Neste espaço, os alunos dedicavam-se ao aprendizado de atividades domésticas, como ao serviço do triclinium. Para maiores informações acerca dos escravos e suas atividades, consultar Mouritsen (2013), Bradley e Cartledge (2011), Wiedemann (2017), entre outros.
}

Romanitas - Revista de Estudos Grecolatinos, n. 16, p. 142-159, 2020. ISSN: 2318-9304. 
para se encaixarem em uma mão pequena. Tal como atualmente, o barulho do chocalho diverte e distrai os bebês, assim como os apitos, semelhantes aos chocalhos, em forma e tamanho, aparecem sob o formato de pássaros (HARLOW, 2013, p. 325). Aliás, o pássaro esteve presente nos sarcófagos infantis. ${ }^{5}$

Entre outros elementos, as representações de animais poderiam indicar o ambiente doméstico das crianças, pois, como propõe Penelope Allison (2018, p. 04), as evidências textuais e pictóricas sinalizam a presença de animais de estimação como cabras, bodes, cães, gatos, pôneis, pássaros, e todos os aqui mencionados aparecem em réplicas de animais, como brinquedos (OMENA; FUNARI, 2020). Neste sentido, podemos verificar algumas imagens que apontam um cenário infantil (Figuras 1 e 2).

Figura 1 - Pequena figura de chumbo representando um cavaleiro com seu cavalo, H. 4,318 cm. Roma, século I-III

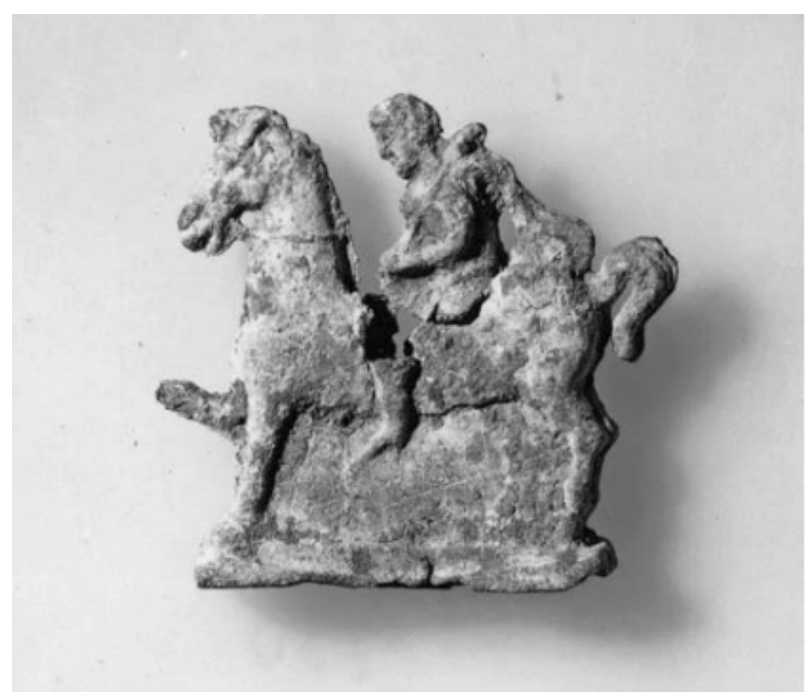

Encontra-se no Courtesy British Museum. Crédito da Imagem: Harlow (2013, p. 328).
Figura 2 - Chocalho de barro seguindo o formato de uma mulher sentada com uma criança em seu colo, H. $16.8 \mathrm{~cm}$. Campania,

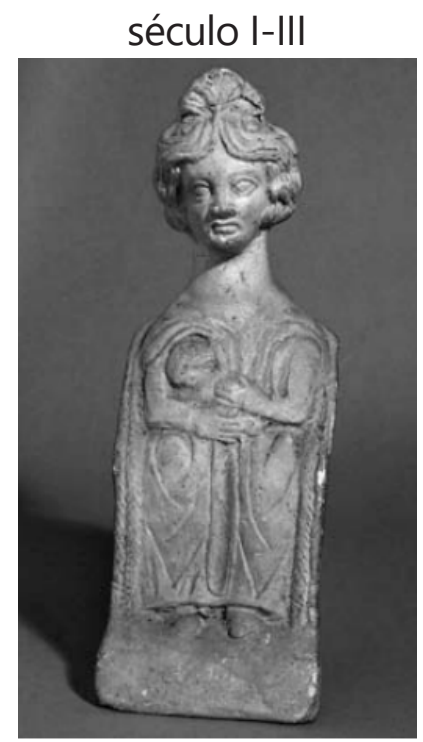

Segundo Harlow (2013, p. 325), esta estatueta pode ser um exemplo de sigillaria (brindes que se davam nas festividades durante as sigillaria. Tal festividade se seguia às saturnais). Crédito da Imagem: Harlow (2013, p. 325).

Como argumenta Harlow (2013, p. 326), alguns desses brinquedos poderiam ser projetados seguindo padrões vinculados às funções e às faixas etárias específicas. Por exemplo, Quintiliano (Inst., I, 26) afirma:

\footnotetext{
${ }^{5}$ Pode-se examinar uma quantidade de artefatos, tendo como exemplo, mamadeiras e imagens de vestimentas para os bebês (CARROLL, 2018a, p. 85, 91). Estas variam de restos reais de cobertores e peças de vestuário, às impressões de tecidos em representações de bandas de panos em corpos de terracota e pedra. Temos, por exemplo, a cabeça de um bebê galo-romano enfaixado em representação votiva de terracota. O artefato encontra-se no Musée Saint-Remi de Reims. Consultar ainda McWilliam (2001, p. 78, 87), Drambra (2007, p. 353, 367), Carroll (2012, p. 41-63), Huskinson (2015, p. 71-72) e Borg (2019, p. 230-231).
} 
Não excluo, porém, aquilo que é conhecido como motivo para estimular a infância para aprender: oferecer também, como diversão, as formas das letras em marfim, ou qualquer outra coisa que se puder encontrar, pela qual essa faixa etária se interesse e lhe seja um prazer manusear, examinar e lhe dar um nome. ${ }^{6}$

Posto isto, o processo pedagógico, sobretudo, em faixas etárias iniciais, entre o nascimento e a idade de sete anos (ALLISON, 2018, p. 04), englobaria práticas associadas ao entretenimento, o que resultaria nas relações entre o brincar e o aprender. No próprio texto, Quintiliano usa o termo infantia, substantivo feminino da primeira declinação, indicando, desse modo, a necessidade do emprego de letras de marfim, já que, segundo sua argumentação, tal prática induziria as crianças ao reconhecimento inicial das letras, em especial devido ao apelo visual das formas e do material de marfim. Supõe-se que algumas das menções de Quintiliano, como, por exemplo, I, 26 e I, 05, referiam-se aos bebês, já que, em todas elas, usa o substantivo feminino infantia, sugerindo, desse modo, um período em que se destaca a incapacidade de verbalização das crianças (SARAIVA, 1993; HORNBLOWER et al., 2012). Quintiliano (Inst., I, 27) acrescenta:

Entretanto, quando a criança começar a acompanhar os traçados das letras, não será inútil gravá-los em tabelas da melhor maneira possível, para que o estilete seja levado por meio delas como sulcos. Pois não se desviará como na cera apenas (de fato será contido por ambas as margens nem poderá sair do espaço determinado) e, seguindo os traços fixados, mais rápida e frequentemente distinguirá os membros da frase e sua mão não precisará da ajuda pela mão superposta de quem a dirige. ${ }^{7}$

É perceptível a urgência em propiciar estratégias para o aprendizado da criança, como, por exemplo, indica Quintiliano nas passagens acerca das letras de marfim $(\mathrm{l}, 26)$ e da construção de tabelas ( $(1,27)$, em que a criança poderia - com o auxílio de um adulto, normalmente um escravo - contornar as letras com um estilete. ${ }^{8}$ Tais evidências indicam não apenas etapas de socialização, mas, sobretudo, a relevância das crianças nas regiões mediterrânicas. Em consonância com as argumentações de Eva Jane Baxter (2008, p. 161), preocupada em problematizar a razão pela qual o estudo das crianças foi omitido nas

\footnotetext{
${ }^{6}$ Non excludo autem, id quod est inventum irritandae ad discendum infantiae gratia eburneas etiam litterarum formas in lusum offerre; vel si quid aliud, quo magis illa aetas gaudeat, inveniri potest, quod tractere, intueri, nominare iucundum sit. ${ }^{7}$ Cum vero iam ductus sequi coeperit, non inutile erit eas tabellae quam optime insculpi, ut per illos velut sulcos ducatur stilus. Nam neque errabit, quemadmodum in ceris (continebitur enim utrinque marginibus neque extra praescriptum egredi poterit) et celerius ac saepius sequendo certa vestigia firmabit articulos, neque egebit adiutorio manum suam manu superimposita regentis.

${ }^{8}$ Como define Bruno Fregni Bassetto (2015, p. 215), tradutor da Institutio Oratoria de Quintiliano, estilete era um "instrumento formado por uma haste pontiaguda com ponta de ferro, bronze ou osso, larga e achatada que servia para escrever em tabuinhas enceradas; a parte oposta, plana, servia para apagar o que se havia escrito. Há indícios de que sua origem seja dos etruscos ou dos gregos. Há ainda outros significados, como um instrumento semelhante, usado no campo da semeadura e outros fins".
} 
interpretações arqueológicas, afirma que as evidências indicam, de fato, crianças como atores sociais e econômicos significativos por si só e que as organizações familiares e suas comunidades priorizaram, geralmente, o cuidado e o treinamento de crianças. Quintiliano é um exemplo, pois centrou-se na formação das crianças. No prefácio de sua Institutio Oratoria, ele reforça:

Como eu considero ser preciso reconhecer que nada é indiferente à arte oratória, sem o que não se pode modelar o orador, nem atingir o auge de qualquer coisa a não ser seguindo os degraus iniciais, não me esquivarei a descer às coisas menores, mas que, caso a negligencieis, não haverá espaço para a maiores; nem começaria de modo diferente, se me fosse confiada a educação de um orador, a orientar seus estudos desde a infância (Quint., Inst., pref., 5). ${ }^{9}$

$\mathrm{Na}$ passagem acima, evidencia-se a relevância da gerência e educação das crianças. O cuidado com a formação dos anos iniciais representava, no futuro - quando se iniciava a educação oratória e, diria, a filosófica -, condições favoráveis ao aprendiz. Aqui, a instrução deveria percorrer a infância do cidadão, por isso a proposta de polidez da ama (Quint., Inst., l, 5). Embora se refira à formação do cidadão, aquele com condições abastadas, afastando-se, portanto, das crianças pobres ou escravas, o retor considerava imprescindível não negligenciar os estudos iniciais.

\section{Olhares em perspectivas: crianças nos espaços da morte em Isola Sacra}

A proposta de Quintiliano se conecta aos enterramentos, à medida que os personagens deveriam pertencer às famílias com recursos financeiros, já que o sepultamento, no Mediterrâneo romano, contava com apenas uma parcela da sociedade: aquela com condições para a construção do edifício funerário ou, pelo menos, que pertencesse aos collegia, associações responsáveis pelo enterramento de seus membros (CARROLL, 2006, p. 46-47). Ademais, as expressões de valorização das crianças repercutem nos espaços mortuários. Meninos e meninas aparecem homenageados em uma grande variedade de suportes, como estelas, altares, retratos, sarcófagos, que registram o luto, o sentimento de perda, a individualidade e seus ambientes de entretenimento, nascimento, educação, entre outros mais.

Assim, como se propõe, o culto aos mortos envolve, por excelência, o enterro, o gênero, a idade, o status e as filiações sociais, pois, tal como se compreende, "os vivos

\footnotetext{
${ }^{9}$ Ego, cum existimem nihil arti oratoriae alienum, sine quo fieri non posse oratorem fatendum est, nec ad ullius rei summam nisi praecedentibus initiis perveniri, ad minora illa, sed quae si negligas, non sit maioribus locus, demittere me non recusabo; nec aliter, quam si mihi tradatur educandus orator, studia eius formare ab infantia incipiam.
} 
falam pelos mortos, simbolizam a si mesmos, representam aquilo que se quer que se pense sobre a família, sobre o grupo social e sobre o morto" (RIBEIRO, 2007, p. 96).

Nesses espaços de memória, é preciso deter o olhar nas inscrições funerárias localizadas nas vias romanas. ${ }^{10}$ Sítios e museus arqueológicos apresentam, hoje, uma infinidade de edifícios, monumentos, afrescos, mosaicos, esquifes e, em quase todos aqui mencionados, constatam-se inscrições de naturezas diversas. Veem-se registros em tijolos, medidas tumulares, referências sobre a quantidade de sarcófagos no recinto (OMENA; FUNARI, 2020), nomes de mortos em afrescos e mosaicos, aspectos legais referentes aos sepultamentos, inscrições em urnas, ânforas e sarcófagos. Em cada uma delas, tem-se a designação não somente de distintos públicos, mas também etapas díspares do ritual aos mortos. Em se tratando dos selos, tem-se, a título de exemplo, a indicação dos produtores de tijolos e a difusão de seus produtos em regiões como Roma, Óstia e Isola Sacra. Nesta, verifica-se o uso heterogêneo de materiais em quase todas as tumbas, indicando, dessa forma, produtos de origens diversas, inclusive, o uso de elementos reutilizados (CAMILLI; TAGLIETTI, 2018, p. 8, 29).

Essas discussões indicam, em especial, uma complexa organização social e espacial presente na arqueologia mortuária. Como parte desse diálogo, o epitáfio cumpre funções ritualísticas e reminiscentes, já que se transforma em escrita mnemônica. Como sugere Aleida Assmann (2011, p. 199),

a escrita não é só medium de eternização, ela é também um suporte da memória. A escrita é, ao mesmo tempo, medium e metáfora da memória. O procedimento da anotação e da inscrição é a mais antiga e, através da longa história das mídias, ainda hoje a mais atual metáfora da memória.

Nesse sentido, as práticas mortuárias, no Mediterrâneo romano, levaram à exploração, empreendida neste estudo, de uma gama diversificada de documentos textuais e materiais. A caminhada tornou possível deparar com discussões retóricas acerca da morte e da infância, pois, como se observa nos vestígios materiais e textuais, a tônica perpassa o cerimonial social. Neles, afrescos, mosaicos, esquifes e epitáfios produzem um cenário de celebrações em que mortos, familiares e comunidade, conectados ao espaço sagrado das necrópoles, aparecem idealizadas em imagens de união, desunião, vitórias aladas, dores, afetos, entre outras. Em Isola Sacra, as crianças aparecem celebradas em epitáfios, ânforas, sarcófagos, compondo, assim, relevos com cenas mitológicas.

${ }^{10}$ Em relação aos estudos espaciais das necrópoles mediterrânicas, pode-se consultar excelentes títulos, tais como: Wallace-Hadrill (2008), Carroll (2011), Pearce (2011), Mander (2012), Campbell (2015) e Jong (2017). 
No museu de Ostia Antica, que se localiza no sítio arqueológico de Óstia, temos alguns fragmentos de sarcófagos de crianças com temáticas que abarcam as narrativas de Menandro, centauromaquias e o deus Atlanta, com procissões dionisíacas e um cippus funerário de mármore com o menino trajando a toga uirilis e com a presença de um bode. O animal compunha o ambiente doméstico das crianças. Neste caso, a coluna em formato de altar pode indicar, segundo se propõe, o animal a ser sacrificado em honra à criança e aos Manes. Ademais, o garoto está ao lado do animal e segura seus chifres. Em suas laterais, do lado direito, vê-se um vaso libatório e, do lado esquerdo, uma forma esférica. Na parte superior do altar, temos uma espécie de papiro aberto que, em suas extremidades e frente, é decorado com rosetas circulares, bastante utilizadas em edifícios tumulares da região itálica. Na parte inferior, temos a inscrição, que se encontra ilegível. Nela, temos indicações dos Dis Manibus - Aos Deuses dos Manes -, inclusive, neste epitáfio, a referência aos deuses não se encontra abreviada e, em fragmento, temos a fórmula ano/meses/dias, indicando o período de vida do menino.

Como aponta Jane Hjarl Petersen (2020, p. 147), a precisão do tempo de vida do ente querido, presente no epitáfio, reflete a incerteza no post mortem. A hora na terra contava; logo, o simbolismo iconográfico representado nas pinturas, nos mosaicos, nos sarcófagos, nas estelas e nos altares indicam rituais de transição entre a vida e a morte e a natureza da vida após a morte. Propõe-se harmonia e prosperidade. Não é sem motivo que a narrativa do altar do menino togado enaltece sua projeção à magistratura e a presença do sacrifício. Abaixo, observa-se a imagem do altar funerário:

Figura 3 - Altar funerário de um menino com a toga uirilis datado do século II

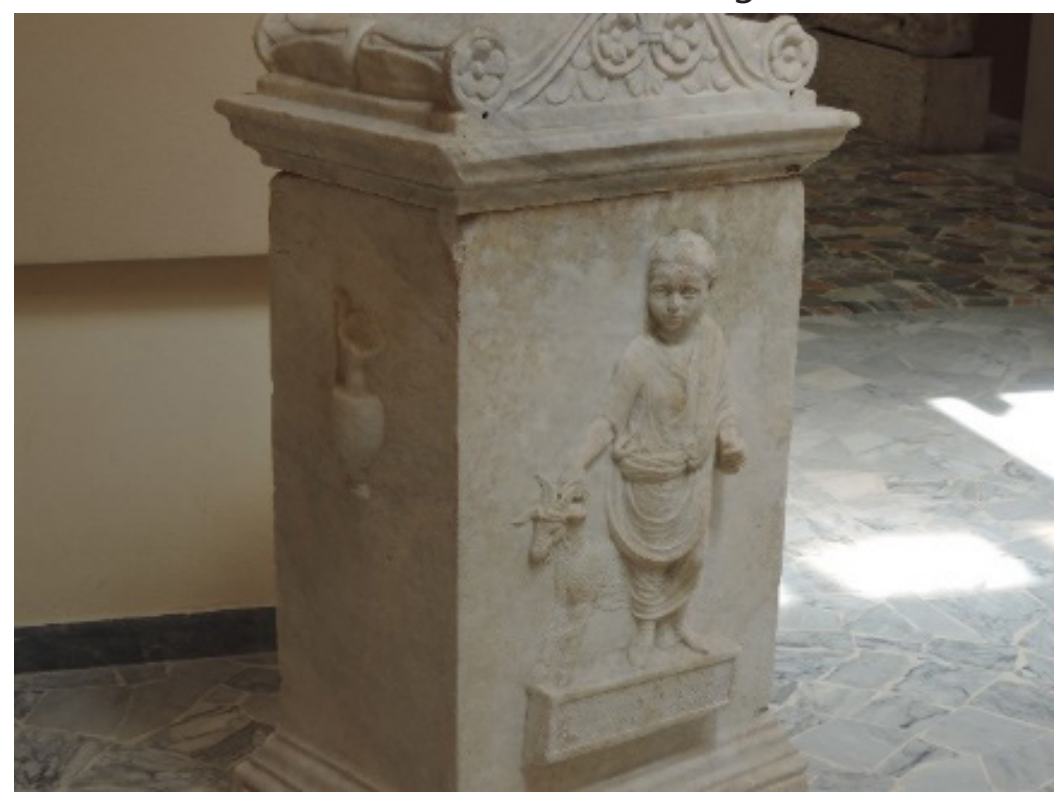

O altar se encontra no Museu Arqueológico de Ostia Antica. Crédito da Imagem: Omena (2014). 
De modo geral, a representação de garotos togados aparece em altares, estelas e relevos, pois, em suas comemorações, os pais normalmente queriam homenagear seus filhos e projetar as carreiras que teriam seguido se não tivessem morrido. Detecta-se a idealização da vida futura das crianças e, segundo argumentamos, buscava-se notabilizar a própria família na comunidade. Marcar e transmitir o acesso dela às magistraturas civis e militares. Se nos referirmos às narrativas das uitae de meninas, veremos sarcófagos com temáticas que exploram, sobretudo, cenários domésticos, em que aparecem com instrumentos musicais que se associavam aos papéis femininos e às virtudes sociais. Fundamentada nos pressupostos de lan Hodder (2012, p. 139-140), Omena $(2018$, p. 197) afirma que:

[...] os rituais mortuários representavam padrões ideológicos, desempenhando, com isso, um papel ativo no mundo social, diríamos dispositivos discursivos (FOUCAULT, 1996). Todavia, tal como lan Hodder, concebemos que os padrões de enterramento e seus respectivos rituais não representavam um espelho imediato da vida. Por exemplo, ao referirmo-nos ao sepultamento de crianças, encontramos em relevos funerários a representação de meninos em idade superior, estando eles vestidos com a toga; no entanto, os estudos dos restos mortais revelam idades inferiores. Então, ao visualizarmos a normatização romana, estes jovens não poderiam entrajar a toga. Ao que nos parece, as crianças tornavam-se construções enunciativas; por isso, inseridas em um espaço mortuário e, portanto, comportamental, refletiam, como sugerem os registros materiais, status social, inserção de seus familiares na comunidade e disputas sociais. ${ }^{11}$

Esse enaltecimento das crianças, quando aparece nos raros epitáfios - pelo menos, em Isola Sacra - acentuam seu tempo de vida, suas relações familiares, inclusive, suas vinculações com o patrono e, normalmente, são adjetivadas como caríssima e piíssima. No entanto, o número baixo de epitáfios não configura a inexistência delas. Habitualmente, as evidências arqueológicas aparecem, sobretudo, nos locais de enterramento e nos objetos de depósitos dos restos mortais, como ânforas e urnas. Por exemplo, na sepultura de número 16 foi encontrada uma tabella defixionis em uma ânfora com os restos mortais de uma criança que possuía entre 3 e 4 anos de idade (BORGIA, 2018). ${ }^{12}$ Assim, evidências

\footnotetext{
${ }^{11}$ Para maiores informações sobre representações funerárias acerca das crianças, consultar Rawson (1999), Huskinson (2007), Mander (2012), Borg (2013), Lovén (2013), Kampen (2015), Koortbojian (2015) e Carroll (2018a).

${ }^{12}$ Como argumentam Omena e Funari (2020, p. 223), "existe ainda o Museo delle Civiltà - Museo Nazionale Preistorico Etnografico "Luigi Pigorini" - localizado na cidade de Roma. Nele, o Departamento de Antropologia Física, com base em técnicas digitais e análises de estudos macro e microscópicos de restos mortais em arcadas dentárias enterradas na Isola Sacra, propôs algumas análises interessantes: as escavações descortinaram cerca de 2000 indivíduos que contabilizavam $35 \%$ de idade não adulta - menor ou igual a 15 anos; média de filhos por mulheres eram seis; adultos - menos de 10\% chegavam aos 50 anos. Além disso, as análises paleodemográficas indicam que a expectativa de vida girava em torno dos 23 anos e a estatura média masculina não superava 1,64 cm, já a feminina girava em torno de 1,52 cm" (Grifo nosso). Ao considerarmos os estudos de Lidewijde de Jong (2017, p. 126-127), o índice de mortalidade infantil, na Síria romana, tal como em Isola Sacra, indica 35\% dos restos dos esqueletos nas sepulturas e, ainda segundo os dados da pesquisadora, as informações de epitáfios e imagens não correspondem aos restos mortais de esqueletos. Crianças
} 
epigráficas aparecem, por exemplo, na tumba de número 96, datada aproximadamente do século II. Localiza-se quase em frente à entrada original do túmulo 97. Possui um caixão semicilíndrico orientado para a estrada, na direção da qual também é colocada a laje de mármore inscrita no centro de um dos lados mais curtos (BALDASSARRE et al., 1996. p. 47-48). A inscrição traz homenagem a uma garota que morreu aos 8 anos, 7 meses e 16 dias:

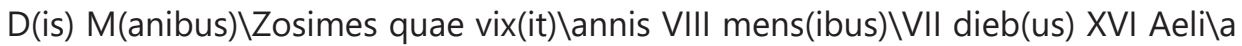
Herois et Ma\ternus Aug(usti) lib(ertus) \tabell(arius) alumnae\carissimae $\backslash$ fecerunt (BALDASSARRE et al., 1996, p. 47-48).

Aos deuses dos Manes. Zosimena que viveu 8 anos, 7 meses e 16 dias. Élia, Heroína e Materno, liberto Augustales, mensageiro, fizeram à filha caríssima (Tradução Luciane Munhoz de Omena).

Neste epitáfio, veem-se as fórmulas correspondentes ao tempo de vida e à dedicatória aos deuses Manes. Normalmente, ambas aparecem nas comemorações aos mortos. Ainda que não apresente versos elegíacos, a mensagem possui uma especificidade interessante: Zosimena teria sido uma criança exposta, pois, de acordo com o texto epigráfico, o termo alumna, substantivo feminino da primeira declinação, indica criança órfã, criada por outras pessoas, e sublinha ainda mais o forte vínculo emocional entre a criança e seus cuidadores. Neste caso, os seus protetores Élia, Heroína e Materno, liberto imperial, que exercia a função de tabellarius, mensageiro, a homenagearam, considerando-a caríssima.

A Epigrafia fornece a melhor evidência para o lugar dos filhos substitutos dentro da família. Por meio de um processo mais informal de adoção, um número de famílias cuidou de crianças, sobretudo, se não conseguissem gerar seus próprios filhos ou se os seus próprios filhos tinham morrido jovens (EDMONDSON, 2015, p. 577). ${ }^{13}$ Como enfatizou Beryl Rawson, órfãos, parentes pobres, crianças abandonadas, ou mesmo jovens escravos, poderiam ser levados por um agregado familiar como alunos; logo, os consideravam seus pais adotivos com companheirismo emocional, em especial na velhice.

De modo geral, acentua-se, quase sempre nas discussões historiográficas, a relação entre pais e filhos ladeada pela inserção na comunidade, seus conflitos e negociações; entretanto, as imagens mortuárias marcam igualmente as dimensões mais emocionais.

e mulheres eram com mais frequência omitidas. Epigrafia e escultura não representavam, portanto, bons indicadores para o sepultamento de crianças. Ademais, túmulos escavados em Beirute e Palmira indicaram poucas crianças, já que se sinalizaram menos enterros arqueologicamente visíveis. As crianças não pertenceriam ao grupo homenageado. Além disso, as crianças do sexo feminino eram menos visíveis, se comparadas ao grupo de enterramento. Não teria sido uma identidade relevante para ser enfatizada na tumba (JONG, 2017, p. 127).

${ }^{13}$ Para maiores informações dos estatutos de crianças órfãs, consultar Hübner e Ratzan (2009). 
Infelizmente, não temos informações sobre a vida de Zosimena. Por exemplo, por que se tornou órfã? Porém, o epitáfio reflete uma domus integrada aos cuidados da criança e um espaço em que a criança é saudada com afeto. Assim, a adjetivação "caríssima", presente no epitáfio, torna-se, de fato, mais emocional. Reflete a vontade de os sobreviventes Hélia, Heroína e Materno - preservarem a memória de Zosimena, a criança amada.

Além do epitáfio a Zozimena, veem-se mais três epitáfios em latim, os quais foram arrolados no catálogo produzido pelos autores Baldassarre et al. (1996). O primeiro se encontra na tumba de número 89 (a), século II, contendo a seguinte homenagem:

Diis Manibus. M(arco) Antonio M(arci) f(ilio) Antonino vixit ann(is) VIII m(ensibus) VII d(iebus) XVII $M$ (arcus) Antonius Zozimus fil(io) piissimo loco donato ab optimis patronis fecit (BALDASSARRE et al., 1996, p. 70).

Aos deuses Manes. Marco Antônio, filho de Marco Antonino, viveu 8 anos, 7 meses e 17 dias. Marco Antônio Zózimo fez (sc. esta sepultura) ao filho pientíssimo. O local doado pelos patronos excelentes (Tradução: Luciane Munhoz de Omena).

O pai, Marco Antônio Zózimo, homenageia o filho Marco Antônio, que viveu 8 anos, 7 meses e 17 dias. Aqui, interessa, sobretudo, o local de depósito dos restos mortais. Antônio, patrono de Zózimo, concede o espaço de sepultamento ao seu filho. Como acentuam Baldassarre et al. (1996), o proprietário do edifício aparece na inscrição, que se encontra na fachada da tumba. O segundo epitáfio, que se refere ao falecimento de um menino, se encontra na tumba de número 74 , datada do século II, e apresenta a seguinte mensagem:

$\mathrm{D}$ (is) $\mathrm{M}$ (anibus). Satyri fecit \lason pater $\mathrm{q}$ (ui) vixit m(ensibus) VIII d(iebus) VIII h(oris) III (BALDASSARRE et al., 1996, p. 94).

Aos Deuses Manes. Sátiro que viveu 8 meses, 8 dias e três horas. lason, seu pai, fez (Tradução Luciane Munhoz de Omena).

Nesta mensagem, o pai de Sátiro, provavelmente liberto, celebra o pouco tempo de vida do filho, indicando, sobretudo, as horas vividas. No último epitáfio, localizado na tumba de número 53, datada aproximadamente do século II, lê-se:

$D$ (is) $M$ (anibus) $\backslash M($ arco) Valerio Fortu $\backslash$ nato Ser(gia) lanuaria $\backslash$ mater fil(io) pie(ntissimo) suo felcit sibi s(uis) vix(it) annis IIIIme(n)s(ibus) VIII d(iebus) XXV. In f(ronte) $p$ (edes) X agro p(edes) X (BALDASSARRE et al., 1996, p. 110).

Aos deuses Manes. Marco Valério Fortunato, filho pientíssimo de Sérgia lanuária, viveu três anos, oito meses e vinte e cinco dias. Fez [a mãe] para o seu, a si e aos seus (sc. esta sepultura). 10 pés de fachada e 10 pés de profundidade (Tradução Luciane Munhoz de Omena). 
A inscrição indica a mãe, Sérgia lanuária, como responsável pela homenagem ao filho, Marco Valério Fortunato. Nela, tem-se a indicação de construção do edifício dedicado ao filho, a ela e aos seus familiares. Normalmente, as mulheres não aparecem como as dedicantes, e sim seus respectivos esposos ou irmãos (OMENA; CARVALHO, 2018). ${ }^{14}$

Embora o marcador emocional não seja explícito, aliás, em nenhum dos quatro conjuntos epigráficos, podemos afirmar que os epitáfios mediterrânicos romanos apresentam um forte vínculo com a produção social de memória e suas celebrações aos entes queridos. Como argumenta Maurren Carroll (2012, p. 48), a investigação dos monumentos funerários possibilita, de fato, a compreensão das formas em que textos e imagens transmitiram os dados acerca da vida das pessoas. Veem-se nomeações dos falecidos, comemoradores e suas relações com familiares, com amigos e com herdeiros reconhecidos publicamente na inscrição. Ainda que Materno acentue o seu ofício de mensageiro, imortalizou a sua relação com Zosimena. Sérgia lanuária celebrou a memória do filho, morto prematuramente. Marco Antônio e Sátiro, mesmo sob um tempo diminuto, tiveram seus nomes homenageados por seus pais. Crianças foram comemoradas. Tornaram-se protagonistas e seus nomes imortalizaram - inclusive, nos dias de hoje - a comunidade de Portus.

\section{Considerações finais}

Neste artigo, foi enfatizada a experiência social infantil em narrativas textuais e materiais. Quintiliano, responsável pelo ensino de retórica, criou estratégias para a formação das crianças e indicou a relevância delas. Sublinhou a socialização das crianças na domus, para, desse modo, construir um cidadão retor. Nos vestígios materiais, brinquedos elaborados para a educação e entretenimento. Na morte, as crianças imortalizaram a si e aos seus familiares, mas, sobretudo, integraram-se à comunidade. Embora não tenhamos um número elevado de epitáfios às crianças, receberam os cuidados aos mortos. Como se destacou na argumentação, as fontes documentais indicam que os adultos não se tornaram imunes ao sofrimento. Pelo contrário, sepultaram seus rebentos.

\footnotetext{
${ }^{14}$ De acordo com Baldassarre et al. (1999, p. 110), a tumba é perpendicular à estrada em que a inscrição menciona o pequeno falecido, Marcus Valerius Fortunatus, o filho piíssimo de Sérgia lanuaria.
} 


\section{Agradecimentos}

Agradeço ao meu amigo e companheiro de área Gilvan Ventura Silva pelo apoio e pela elaboração do dossiê sobre a infância na Antiguidade. Agradeço a ele, à Margarida Maria de Carvalho, à Ana Teresa Marques Gonçalves, ao Pedro P. A. Funari e ao Thiago Eustáquio Araújo Mota pelos constantes diálogos e trocas de ideias. As reflexões desenvolvidas no decorrer do texto são de responsabilidade apenas da autora.

\section{Referências}

\section{Documentação textual}

PLUTARCH. Moralia. Translation by Frank Cole Babbitt. Cambridge: Harvard University Press, 1927. v. 1.

QUINTILIANO. Instituição Oratória. Tradução, apresentação e notas de Bruno Fregni Bassetto. Campinas: Editora Unicamp, 2015. t. 1.

\section{Obras de referência}

HORNBLOWER, S. et al. (ed.). The Oxford Classical Dictionary. Oxford: Oxford University Press, 2012.

SARAIVA, F. R. S. Novíssimo dicionário Latino-Português. Etimológico, prosódico, histórico, geográfico, mitológico, biográfico, etc. Rio de Janeiro: Garnier, 1993.

\section{Catálogos}

BALDASSARRE, S. et al. (ed.). Necropoli di Porto. Isola Sacra. Roma: Istituto Poligrafico e Zecca dello Stato, 1996.

PESSOA, M. et al. (ed.). Crianças de hoje e de ontem no cotidiano de Conimbriga. Conimbriga: Empresa Gráfica, 2000.

\section{Obras de apoio}

ALLISON, P. Roman household organization. In: CRAWFORD, S.; HADLEY, D. M.; SHEPHERD. G. (ed.). The Archaeology of Childhood. Oxford: Oxford University Press, 2018, p. 0118. 
ASSMANN, A. Espaços da recordação: formas e transformações de memória cultural. Campinas: Editora Unicamp, 2011.

BASSETTO, B. F. Notas. In: QUINTILIANO. Instituição Oratória. Campinas: Editora Unicamp, 2015, p. 215-225. t. 1.

BAXTER, J. E. The Archaeology of Childhood. Annual. Review of Anthropology, v. 17, n. 37, p. 159-175, 2008.

BORG, B. E. Crisis \& ambitio: tombs and burial customs in Third Century CE Rome. New York: Oxford University Press, 2013.

BORG, B. E. Roman tombs and the art of commemoration: contextual approaches to funerary customs in the second century CE. Cambridge: Cambridge University Press, 2019.

BORGIA, E. Una tabella defixionis dalla necropoli dell'Isola Sacra. In: GERVAZONI, M. C. et al. (ed.). Ricerche su Ostia e il suo territorio. Rome: École Française de Rome, 2018, p. 1-25.

BRADLEY, K.; CARTLEDGE, P. (ed.). The Cambridge world History of Slavery: the Ancient Mediterranean World. Cambridge: Cambridge University Press, 2011.

CAMILLI, L.; TAGLIETTI, F. Contributi per un'archeologia di cantiere: i bolli laterizi dalla necropoli di Porto all'Isola Sacra. In: GERVAZONI, M. C. et al.(ed.). Ricerche su Ostia e il suo territorio. Rome: École Française de Rome, 2018, p. 1-51.

CAMPBELL, V. L. The tombs of Pompeii: organization, space, and society. New York: Routledge, 2015.

CARROLL, M. Infancy and earliest childhood in the Roman world. London: Oxford University Press, 2018a, p. 82-117.

CARROLL, M. Memoria and 'damnatio memoriae': preserving and erasing identities in Roman funerary commemoration. In: CARROLL, M.; REMPEL, J. (ed.). Living through the dead burial and commemoration in the Classical world. Oakville: The David Brown Book, 2011, p. 65-90.

CARROLL, M. No part in earthly things: the death, burial and commemoration of newborn children and infants in Roman Italy. In: HARLOW, M.; LOVÉN, L. L. (ed.). Families in the Roman and Late Antique World. London: Continuum International, 2012, p. 41 63.

CARROLL, M. Archaeological and epigraphic evidence for infancy in the Roman World. In: CRAWFORD, S.; HADLEY, D. M.; SHEPHERD. G. (ed.). The Archaeology of Childhoold. Oxford: Oxford University Press, 2018b, p. 1-24.

CARROLL, M. Spirits of the dead: Roman funerary commemoration in Western. Oxford: Oxford University Press, 2006. 
CRAWFORD, S.; HADLEY, D.; SHEPHERD, G. The Archaeology of Childhood: the birth and development of a discipline. In: (ed.) The Oxford handbook of the Archaeology of Childhood. Oxford: Oxford University Press, 2018, p. 01-45.

DAMBRA, E. Racing with death: circus sarcophagi and the commemoration of children in Roman Italy. In: COHEN, A.; RUTTER, J. B. (ed.) Constructions of childhood in Ancient Greece and Italy. Athens: The American School of Classical Studies at Athens, 2007, p. 339-351.

EDMONDSON, J. Roman family history. In: BRUUN, C.; EDMONDSON, J. (ed.). Roman epigraphy. Oxford: Oxford University Press, 2015, p. 559-581.

FERREIRA, J. R. A criança e o brinquedo no tempo do domínio romano na província da Lusitânia. In: PESSOA, M. et al. (ed.). Crianças de hoje e de ontem no cotidiano de Conimbriga. Conimbriga: Empresa Gráfica, 2000, p. 42-51.

FOUCAULT, M. Ordem do discurso. São Paulo: Loyola, 1996.

GOLDEN, M. Other people's children. In: RAWSON, B. (ed.). A companion to families in the Greek and Roman Worlds. Oxford: Wiley-Blackwell, 2011, p. 262275.

GRUBBS, J. E.; PARKIN, T.; BELL, R. Introduction. In: (ed.). The Oxford handbook of childhood and education in the Classical World. Oxford: Oxford University Press, 2013, p. 1-17.

GUARINELLO, N. L. Uma morfologia da história: as formas da História Antiga, Politéia, v. 3, n. 1, p. 41-62, 2003.

GUARINELLO, N. L. Arqueologia e cultura material. In: BRUNO, M. C. O.; CERQUEIRA, F. V.; FUNARI, P. P. A. (org.). Arqueologia do Mediterrâneo Antigo. Campo Grande: Life, 2011, p. 161-168.

HARLOW, M. Toys, dolls, and the material culture of Childhood. In: GRUBBS, J. E.; PARKIN, T.; BELL, R. (ed.). The Oxford handbook of childhood and education in the Classical World. Oxford: Oxford University Press, 2013. p. 322-340.

HODDER, I. The presente past: an introduction to Anthropology for archaeologists. England: Pen \& Sword, 2012.

HÜBNER, S. R.; RATZAN, D. M. Fatherless Antiquity? Perspectives on fatherlessness in the Ancient Mediterranean. In: . (ed.). Growing up fatherless in Antiquity. Cambridge: Cambridge University Press, 2009, p. 3-28.

HUSKINSON. J. Constructing childhood on Roman funerary memorials. Hesperia Supplements, v. 41, p. 323-338, 2007.

HUSKINSON. J. Roman strigillated sarcophagi: Art and Social History. Oxford: Oxford University Press, 2015. 
JONG, L. The Archaeology of death in Roman Syria: burial, commemoration and Empire. Cambridge: Cambridge University Press, 2017.

KAMPEN, N. Roman Art and Gender Studies. In: BORG, B. E. (ed.). A companion to Roman Art. Oxford: Blachwell, 2015, p. 71-92.

KEEGAN, P. Reading the 'pages' of the 'Domus Caesaris': 'pueri delicati', slave education, and the graffiti of the Palatine paedagogium. In: GEORGE, M. (ed.). Roman slavery and Roman material culture. Toronto: University of Toronto Press, 2013, p. 69-98.

KOORTBOJIAN, M. Roman sarcophagi. In: BORG, B. E. A companion to Roman Art. Oxford: Wiley-Wiley-Blackwell, 2015, p. 286-300.

LOVÉN, L. L. Children and childhood in Roman Commemorative Art. GRUBBS, J. E.; PARKIN, T.; BELL, R. (ed.). The Oxford handbook of childhood and education in the Classical World. Oxford: Oxford University Press, 2013, p. 302-321.

MACNIVEN, T. J. Behaving like a child: immature gestures in Athenian vase painting. In: COHEN, A.; RUTTER, J. B. (ed.). Constructions of childhood in Ancient Greece and Italy. Athens: The American School of Classical Studies at Athens, 2007, p. 85-100.

MANDER, J. The representation of physical contact on Roman tombstones. In: HARLOW, M.; LOVÉN, L. L. (ed.). Families in the Roman and Late Antique World. London: Continuum International, 2012, p. 64-84.

MCWILLIAM, J. Children among the dead: the influence of urban life on the commemoration of children on tombstone inscriptions. In: DIXON, J. (ed.) Childhood, class and kin in the Roman World. London: Routledge, 2001, p. 74-98.

MOURITSEN, $H$. Slavery and manumission in the Roman elite: a study of the Columbaria of the Volusii and the Statilii. In: GEORGE, M. (ed.). Roman slavery and Roman material culture. Toronto: University of Toronto Press, 2013, p. 43-68.

OAKLEY, J. H. Children in Archaic and Classical Greek art: a survey. In: GRUBBS, J. E.; PARKIN, T.; BELL, R. (ed.). The Oxford handbook of childhood and education in the Classical World. Oxford: Oxford University Press, 2013, p. 145-171.

OMENA, L. M. As tessituras da morte: reflexões sobre a necrópole de Isola Sacra. In: SILVA, G. V.; SILVA, E. C. M.; NETO, B. M. L. Usos do espaço no mundo Antigo. Vitória: GM, 2018, p. 190-218.

OMENA, L. M.; CARVALHO, M. M. Family, memory and death in the tomb inscriptions of Mediolanum (I-II AD). Heródoto, v. 3, n. 1, 2018. p. 355-373. 
OMENA, L. M.; FUNARI, P. P. A. A recordação funerária na Isola Sacra. In: CARVALHO, M. M.; OMENA, L. M. (ed.). Narrativas e materialidades sobre a morte nas Antiguidades Oriental, Clássica e Tardia. Curitiba: CRV, 2020, p. 227-248.

PEARCE, J. Marking the dead: tombs and topography in the Roman provinces. In: CARROLL, M.; REMPEL, J. (ed.). Living through the dead burial and commemoration in the Classical world. Oakville: The David Brown Book, 2011, p. 134-158.

PETERSEN, J. H. Protecting me every step of the way: Dionysian symbolism in the burial culture of Roman Ostia. In: BARGFELDT, N.; PETERSEN, J. H. (ed.). Reflections: harbour city deathscapes in Roman Italy and beyond. Rome: Analecta Romana Instituti Danici, 2020, p. 145-168.

RAWSON, B. Children and childhood in Roman Italy. Oxford: Oxford University Press, 2003. RAWSON, B. The iconography of Roman childhood. In: RAWSON, B.; WEAVER, P. (ed.). The Roman in family: status, sentiment, space. Oxford: Oxford University Press, 1999, p. 205-232.

RIBEIRO, S. M. Arqueologia das práticas mortuárias: uma abordagem historiográfica. São Paulo: Alameda, 2007.

SOUSA, L. N. Havia entre os atenienses do período clássico a ideia de infância? Uma possibilidade de análise do diálogo entre a cerâmica grega e a Filosofia. Revista de História da UEG, n. 8, v. 2, p. 1-19, 2019.

TUAN, Yi-Fu. Espaço e lugar: a perspectiva da experiência. São Paulo: Difel, 1983.

WALLACE- HADRILL, A. Housing the dead: the tomb as house in Roman Italy. In: BRINK, L.; GREEN, D. (ed.). Commemorating the dead: texts and artifacts in context. New York: Walter de Gruyter, 2008. p. 39-77.

WIEDEMANN, T. Greek and Roman slavery. London: Routledge, 2017. 